\title{
Toward a Rule-Based Biome Model
}

Ronald P. Neilson, George A. King, and Greg Koerper

\begin{abstract}
Current projections of the response of the biosphere to global climatic change indicate as much as 50 to $90 \%$ spatial displacement of extratropical biomes. The mechanism of spatial shift could be dominated either by competitive displacement of northern biomes by southern biomes or by drought-induced dieback of areas susceptible to change. The current suite of global biosphere models cannot distinguish between these two processes, hence the need for a mechanistically based biome model. The first steps have been taken toward development of a rule-based, mechanistic model of regional biomes at a continental scale. The computer model is based on a suite of empirically generated conceptual models of biome distribution. With a few exceptions, the conceptual models are based on the regional water balance and the potential supply of water to vegetation from two soil layers: surface for grasses and deep for woody vegetation. The seasonality of precipitation largely determines the amount and timing of recharge of each of these soil layers and, thus, the potential mixture of vegetative life-forms that could be supported under a specific climate. The current configuration of rules accounts for the potential natural vegetation at about $94 \%$ of 1,211 climate stations over the conterminous United States. Increased temperatures, due to global warming, would: (1) reduce the supply of soil moisture over much of the United States by reducing the volume of snow and increasing winter runoff, and (2) increase the potential evapotranspiration (PET). Combined, these processes would likely produce widespread drought-induced dieback in the Nation's biomes. The model is in an early stage of development and will require several enhancements, including: explicit simulation of PET, extension to boreal and tropical biomes, a shift from steady-state to transient dynamics, and validation on other continents.
\end{abstract}

Trace-gas-induced global climatic change has been projected to potentially shift the world's major biotic regions by hundreds of kilometers (Smith and Tirpak 1989). Under one scenario, as much as $55 \%$ of the world's terrestrial vegetation could change to a different type (Smith et al. in prep.; King et al. in prep.). Such changes could produce complicated feedbacks to the global climate, possibly exacerbating the "greenhouse effect", and would certainly produce significant ecological and economic upheavals. These projections are based, in part, on the Holdridge life-zone approach, which correlates the distribution of major vegetation types to annual precipitation, potential evapotranspiration, and biotemperature (Holdridge 1967).

Another global biome model (Box 1981), which is more detailed in climate parameters, is also correlational. The two approaches generally agree on the direction of mid- to high-latitude vegetation changes under $2 \times \mathrm{CO}_{2}$ but disagree on the sign of the change in the tropics. The tropical forests expand under the Holdridge model, but contract under the Box model (Smith $e t$ al. in prep.; King $e t$ al. in prep.). Both approaches assume a steady state; that is, they cannot simulate the transition of biomes from one type to another.

The accuracy with which these approaches predict current vegetation ranges from $<50 \%$ to about $77 \%$ (Prentice 1990; Stephenson 1990). These models also do not simulate biosphere/atmosphere feedbacks. These and other limitations suggest the need for a more mechanistic approach to biome modeling - one that can be incrementally developed to

In: J.L. Betancourt and V.L. Tharp, editors. 1991. Proceedings of the Seventh Annual Pacific Climate (PACLIM) Workshop, April 1990. California Department of Water Resources. Interagency Ecological Studies Program Technical Report 26. 
incorporate transient behavior, ecosystem productivity, trace gas emissions, and disturbance regimes (e.g., wildfire).

An approach to biome modeling now being developed is more closely related to physiological plant processes. The intent is to simulate distinct life-forms or physiognomies (Beard 1978), mixtures of which produce different biomes. The model was constructed from the premise that the climate is the principal determinant of global vegetation distribution and that variations in topography, soils, disturbance regimes, and biotic interactions modify these distributions (Allen and Starr 1982, Neilson et al. 1989, O'Neill et al. 1986, Stephenson 1990, Vankat 1979, Woodward 1987). Construction of the preliminary version of the model represents a partial test of this premise. Successful classification of vegetation based exclusively on climatic information will be viewed as supportive of the premise. The present approach is limited to steady-state, potential natural vegetation. Future enhancements should include land-use considerations. Model development so far has been limited to the conterminous United States but will be extended to global vegetation in future versions.

\section{Conceptual Development}

New developments in biogeography are providing a mechanistic conceptualization of the biosphere (Bryson 1966, Neilson and Wullstein 1983, Neilson 1986, Neilson 1987, Neilson et al. 1989, Stephenson 1990, Woodward 1987). The model described here is based on mechanistic, conceptual models described by Neilson et al. (1989). These resulted from transect analyses of over 1,200 weather stations in the conterminous United States (Figure 1) and over 7,000 U.S. Geological Survey gaging stations (Quinlan et al. 1987, US West 1988a, US West 1988b). The approach relates the seasonality of temperature, precipitation, and runoff patterns to the physiological requirements of plants during different parts of their life cycles and seasonal cycles. Details of the approach and results are published in Neilson et al. (1989).

The continental transects of climate and runoff revealed regional patterns of climate and runoff seasonality that coincide with the boundaries of the major biomes of the United States (Figure 2) (Neilson et al. 1989). These generalizations form the basis for the model development described here and can be cast as rules for prediction of the occurrence of woody vegetation, grasslands, and deserts. Woody vegetation in the United States appears to receive enough winter precipitation to recharge a deep soil reservoir. Deep soil water is apparently required to balance the PET (potential evapotranspiration) during the growing season. If the amount of winter precipitation is large, a region will support a closed forest. Intermediate amounts should support a lower stature or open forest (e.g., savanna or pinyon-juniper woodland); lesser amounts should support a shrubland. The amount of winter precipitation (i.e., deep soil water) required is a function of growing season PET and rainfall minus runoff. Regional runoff patterns suggest that the deep soil reservoir is virtually depleted each year by transpiration and runoff.

These observations are consistent with current theory and plant physiology (Neilson et al. 1989, Stephenson 1990, Woodward 1987). If excess water were available in deep soil layers at the end of a growing season and ecosystems were not energy- or nutrient- limited, they should increase biomass and leaf area in subsequent seasons, thus increasing the rate of withdrawal of deep soil water. If leaf area over a landscape were so high that the rate of 


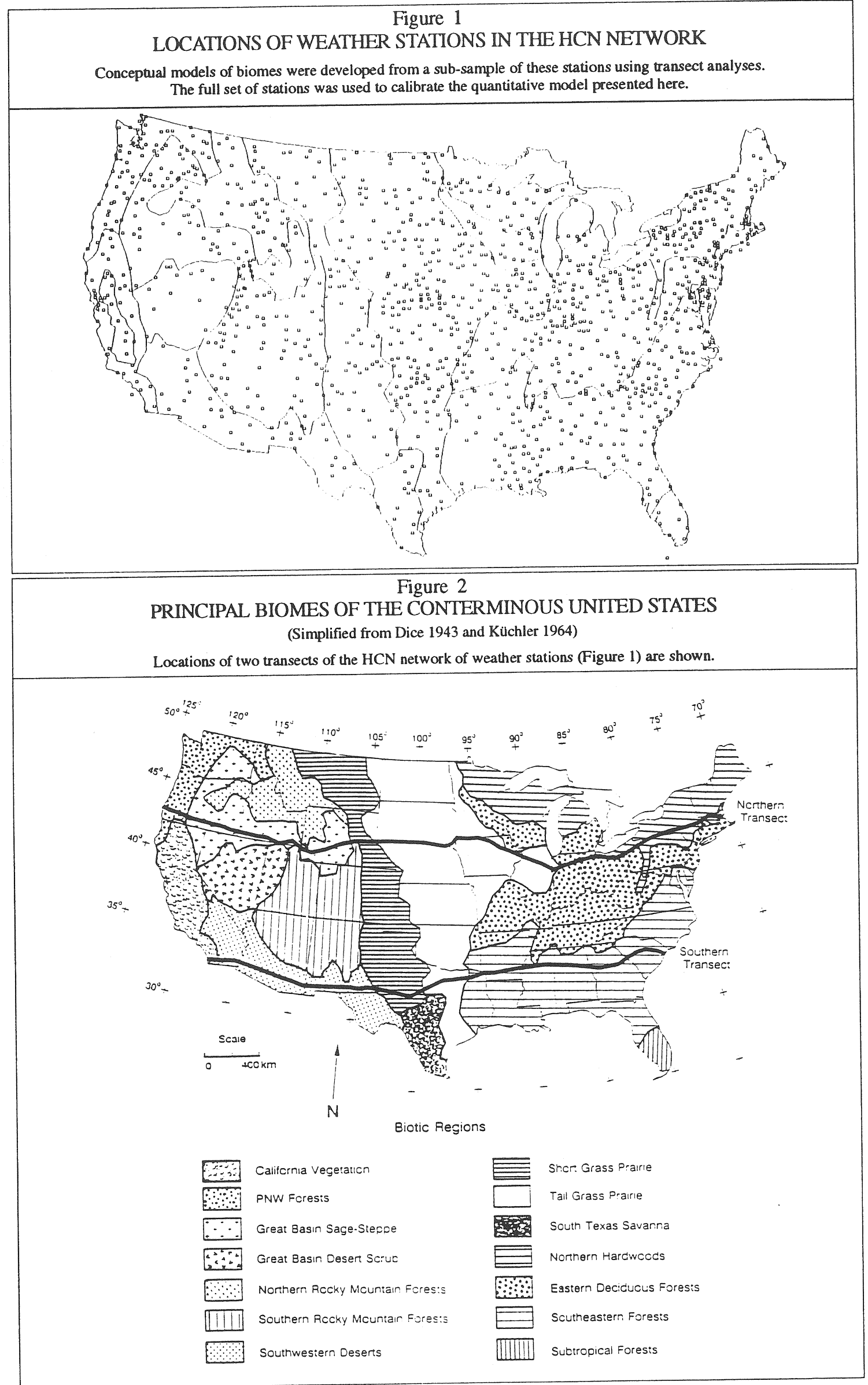


water withdrawal completely depleted deep soil water, then plants would die or leaves and branches would be sloughed (Woodward 1987). Leaf area would be reduced, as would the rate of withdrawal of deep soil water. Thus, in theory, ecosystems should be in dynamic equilibrium (steady state) with the regional water balance by virtue of these intrinsic feedback processes.

While maintenance of woody vegetation appears to require deep soil water, maintenance of grasses appears to require sufficient surface soil moisture during growth and reproduction, usually the spring to summer months. Mixtures of the two life-forms can occur if there is enough moisture in the appropriate soil layers during the growing season and if interference by one life-form does not preclude existence of the other. Grasslands can occur if the woody canopy is open enough to allow high light penetration to the soil surface and if there is a sufficient supply of surface soil moisture during the active growing season of grasses, generally spring (Neilson 1987, Neilson et al. 1989). This implies a sufficiently low level of deep soil water that a closed forest would be precluded from the site. If spring rains are accompanied by high midsummer rains, surface soil will remain moist and a large stature grassland should be supported (e.g., the tall grass prairie). If both winters and springs are quite dry, maintenance of both woody vegetation and grasses is hindered, and a desert may be expected. High midsummer rains in such a desert area can support a low-stature grassland, as in the Chihuahuan and Sonoran deserts of the Southwest (Neilson 1986, Neilson 1987).

A few biome boundaries in the United States appear to be directly controlled by cold temperature rather than by water balance. The most prominent of these are:

- The boundary of the temperate forests with the boreal forest (Burke et al. 1976).

- Possibly the boundary between the Southeast pines and hardwoods with the oak-hickory forest to the north (Neilson et al. 1989).

The current configuration of our biome model does not address these boundaries.

The model is being developed in stages that will progress from empirical and correlational to simulation of water balance and thermal constraints. The empirical rules described here are generally adequate to define most dominant vegetation types in the conterminous United States. In our model, threshold values of precipitation amounts during different seasons determine transitions between different life-forms, as described above. This configuration addresses the supply side of the water balance. The demand function, PET, is assumed to be fixed and is not directly factored into the rules. Given the assumption of fixed PET, the current configuration of the rules cannot be used to assess future climate effects. This initial version of the model was constrained by the unavailability of data for the physically based calculation of PET at large spatial scales. PET will be incorporated in later versions.

The rules allow mixtures of life-forms, such as trees and grasses, if the canopy is open. These mixtures can produce complicated biotic interactions and disturbance regimes. For example, the eastern deciduous forest is characterized by both wind and fire disturbances, with wind perhaps the most important (Runkle 1985). However, the adjacent prairie supports a natural, high-frequency fire regime (Abrams et al. 1986, Vankat 1979). If the 
tree canopy is open, such that a well developed grass layer forms, woody vegetation is at risk from fire. The presence of high grass biomass also places woody vegetation at risk from herbivores and from competition for both light and water between shrub seedlings and rapidly growing grasses. Under these conditions, strictly climatic rules for prediction of biome physiognomy will not suffice. Secondary influences from disturbance and biotic interactions are important and can remove one or more climatically favored life-forms (Abrams et al. 1986, Vankat 1979). Therefore, under certain climatic conditions where specific mixtures are favored, secondary rules are invoked to modulate the biome physiognomy. Variations in soil infiltration rates, water-holding capacity, and nutrient status will also require secondary rules.

The demand function - PET minus growing season rainfall - will determine the amount of supplemental soil water required by different life-forms during different seasons in future versions of the model. Enhanced versions of the model will be operable under future climate. Additional enhancements will include dynamic simulation of regional water balance, using an energy balance approach with vegetation and leaf area acting as conduits between the soil and the atmosphere (Federer 1982, Woodward 1987). Model development and calibration are being achieved using the site-specific monthly data from the 1211-station HCN (Historical Climatology Network) (Figure 1, Quinlan et al. 1987). Once calibrated, the model will be operated on a distributed climate over a dense grid.

\section{Model Description}

The model was constructed as a set of rules based on the conceptual models of Neilson et al. (1989). The entire HCN was used to calibrate the rules. Each station was pre-classified to a specific biome based on a map modified from Küchler (1964) and Dice (1943). The stations were then processed through the rule-base and classified accordingly. Accuracy was determined by comparison between pre- and post-classifications. Parameter adjustment and calibration were dependent on visual interpretation of the mapped residuals. Error in classification can arise from either the pre-classification or the rule-based classification. A careful analysis of the residuals is necessary to determine the source of the error.

The most unique feature of the model is the temperature-based definition of seasons. Winter, spring, and summer are the principal seasons considered. Temperature thresholds, input as parameters, were used to define the beginning and end of the seasons (Figure 3). Therefore, the length of seasons automatically scales with latitude, altitude, and continentality. A map of precipitation during any one season would not represent precipitation amounts over the same period at all map locations.

The beginning and end of winter are defined from both hydrologic and biotic perspectives. In temperate zone summers, PET is generally high enough that incident precipitation does not infiltrate to deep soil layers, but either runs off directly or is evapotranspired from vegetation surfaces and surface soil layers (Major 1963, Thornthwaite 1948, Thornthwaite and Mather 1955). In cooler months, PET is low enough that incident precipitation can infiltrate to deep soil layers. Accumulated snow will also infiltrate or run off as it melts. Thus, we define a temperature threshold above which precipitation cannot reach deep soil layers and below which it can. The infiltration period defines winter in temperate latitudes. The threshold also carries a biotic importance in that it closely relates to the timing of dormancy onset and release in plants. 


\section{Figure 3}

\section{EXAMPLE OF RULE-BASED PARTITIONING OF THE SEASONS}

Precipitation $=$ Open Circles; Temperature $=$ Open Squares; Potential Evapotranspiration $=$ Closed Circles Vertical dotted lines indicate locations of temperature thresholds used in the model to delineate seasonal transitions. Temperature thresholds are used to define the beginning and end of seasons for each weather station. Within each season, precipitation amounts are accumulated for seasonal totals or examined in terms of precipitation per month. Different rainfall amounts within the different seasons are used by the rule-base to differentiate between different life-forms that would potentially be supported by that climate.

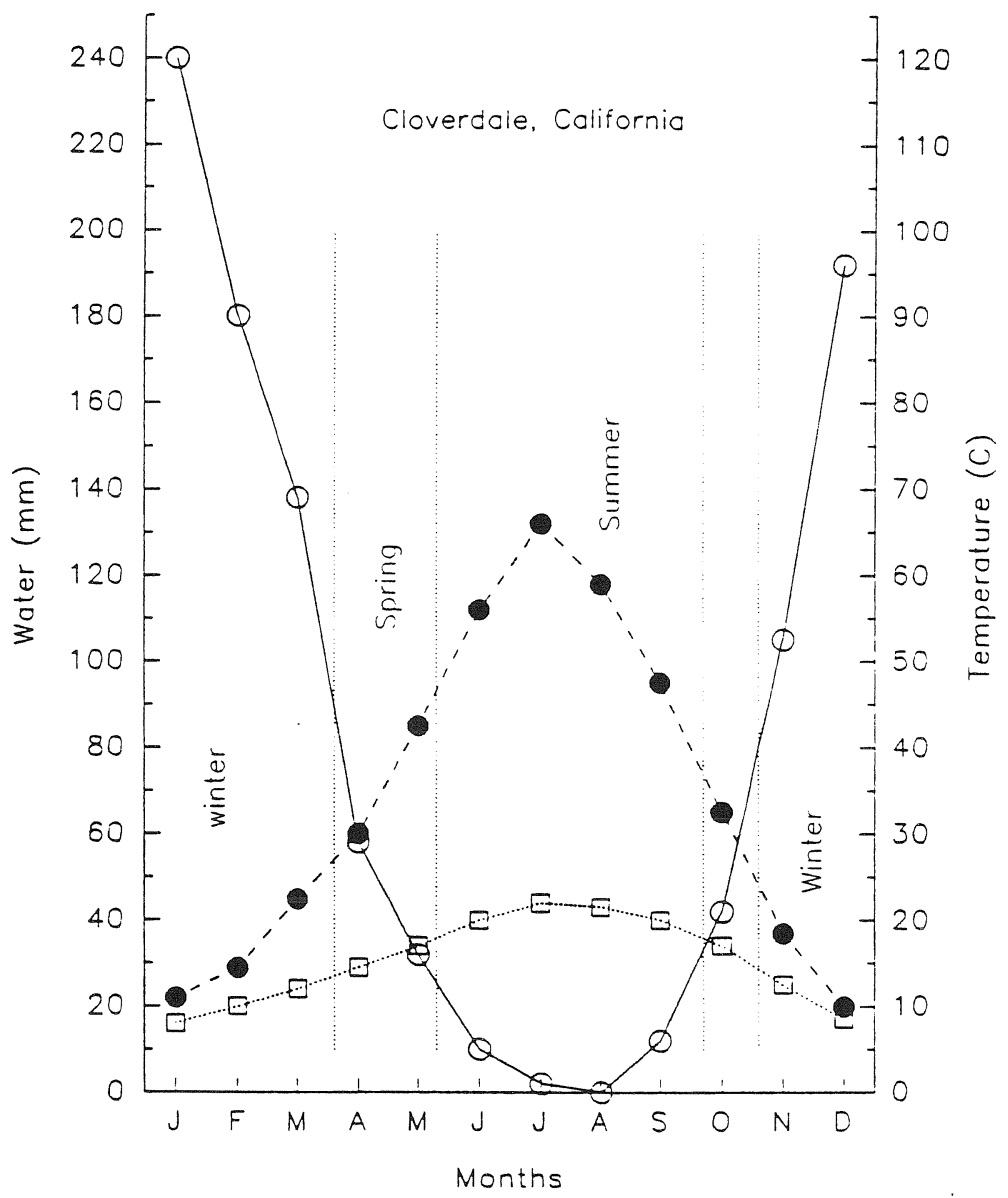

Spring is viewed from the hydrologic perspective as the period over which the surface soil layer can be depleted. This period is critical for seedling establishment of woody species and for completion of the life cycles of grasses and ephemerals. In the temperate zone, the surface soil will dry rapidly in the absence of spring rains, precluding a major grassland development. In northern states under these rules, winter can extend to quite late in the year and spring can extend through most of the growing season, with little to no summer.

Summer is generally the period of greatest water stress. If spring is wet enough, grasses can complete their life cycles before critical mid-summer drought stress (Vankat 1979). However, if summers are also wet, different grass species can continue to grow, producing a mixed or tall grass environment.

There are two classes of parameters in the model:

- Temperature thresholds that define the beginning and ending of seasons.

- Precipitation thresholds within seasons that constrain the life-forms dependent on that season. 
Figure 4 is a model flow chart showing the decision tree applied to each meteorological record of monthly temperature and precipitation. Winter precipitation thresholds are configured as absolute amounts, since the timing of precipitation is not critical. That is, of all the accumulated precipitation during the winter, a fixed fraction is assumed to infiltrate to deep soil layers at some time during winter, with the remainder being returned to the atmosphere (evaporation, sublimation) or routed to surface water (runoff). However, during spring and summer, the supply of water (precipitation) and demand for water (evapotranspiration) are essentially simultaneous when viewed from a monthly time-step. Therefore, precipitation thresholds during spring and summer are defined in units of millimeters per month.

The rules are equivalent to a dichotomous key with simple yes/no decisions determining the trajectory through the rules and the ultimate declaration of biome type for a station (or cell, if applied to a full grid). The flow chart is arranged such that all winter decisions are in the first column of diamond shapes, followed by a column of spring decisions and a column of summer decisions. The decisions enclosed by dashed lines (rules 11 and 13) are implied rather than explicitly coded rules in the current configuration. The implied rules arise from assuming the application of secondary biome rules for biotic interaction and disturbance regimes. The bubbles to the left of the flowchart are the simplified classifications applied at the termination of the adjacent rule. They indicate the influence of the secondary, implied rules accounting for fire and biotic interactions. For example, a mixture of open-canopy, deciduous trees with tall grass prairie is directly classified as tall grass prairie. Similarly, all Pygmy forests (pinyon-juniper woodland), with or without grass, are classified as Pygmy forest. Future versions of the model will retain all such mixtures and distinctions.

The calibrated threshold separating closed forest from non-closed forest is $375 \mathrm{~mm}$ of winter precipitation (rule 2). The amount of summer precipitation per month (rule 3 ) separates broadleaf from conifer forests. The physiological inference is that broadleaf trees cannot withstand the degree of mid-summer vapor-pressure stress across the leaf surface that conifers can withstand (Marshall and Waring 1984, Neilson et al. 1989, Running 1975, Waring and Franklin 1979).

The current configuration of the model becomes inadequate as the stations approach subtropical climates. Rule 4 is a temporary proxy for a set of rules that will deal with subtropical climates. As you approach the Florida peninsula, winters become ever shorter and eventually nonexistent as defined by the temperature thresholds. Thus, precipitation at these stations during winter is not sufficient to support a forest, a clear artifact of the rules. As the growing season becomes longer, the infiltration period of winter becomes shorter. Under these situations, infiltration can still occur if the amount of rainfall more than compensates for a high PET. This does occur in forested areas in the subtropical climates of the southeastern United States and elsewhere (Neilson et al. 1989). However, implementation of such a rule must await a future version of the model that incorporates physically based PET calculations. A workable place-holder is a threshold for annual precipitation of about $1100 \mathrm{~mm}$, given that winter precipitation is below a closed-forest threshold (rule 4). This correctly classifies closed-forest stations in the far southeastern United States, yet does not interfere with appropriate winter rule-based decisions in more northerly latitudes. 


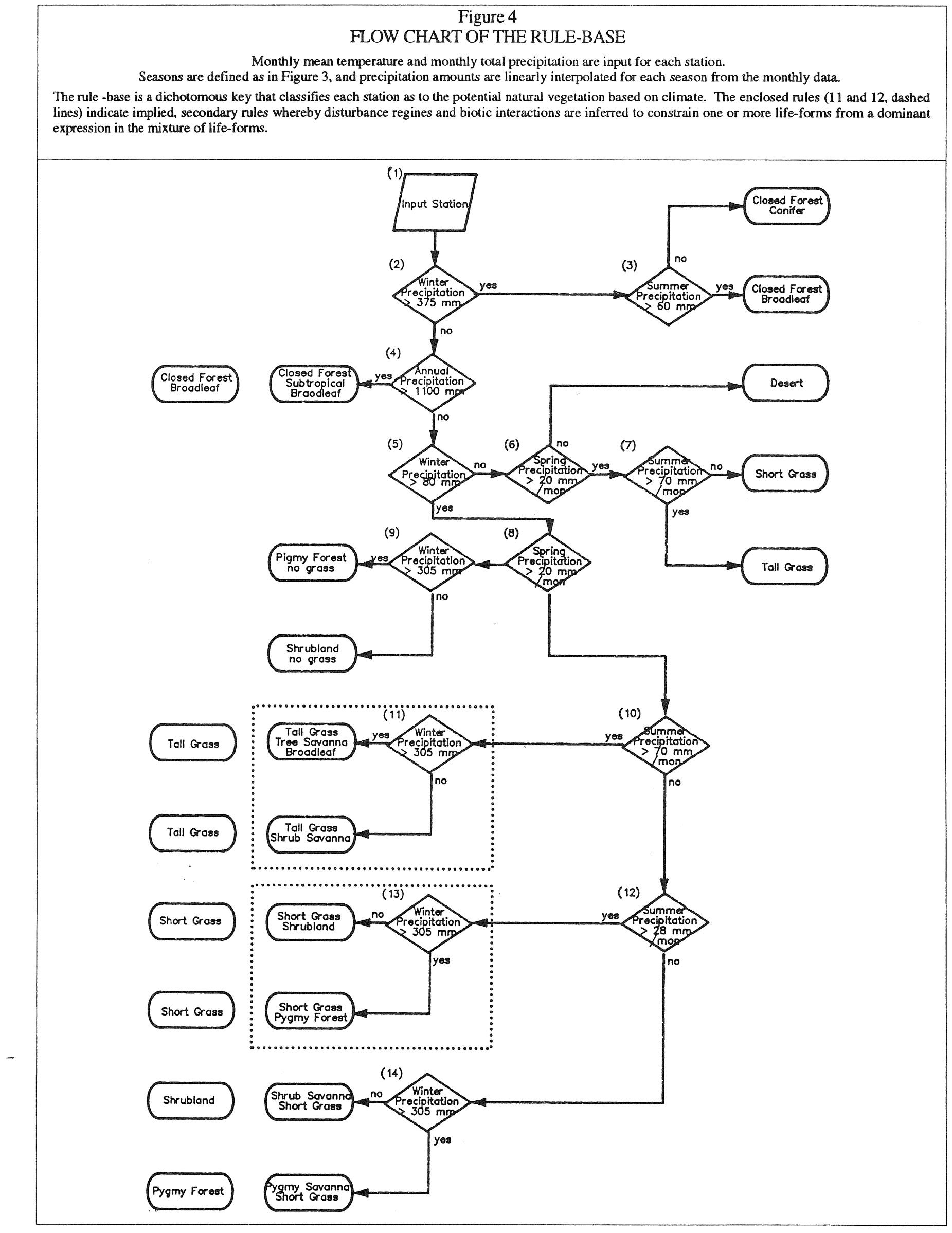


After partitioning the high winter precipitation (i.e., closed-forest stations), rule 5 selects sites with winter precipitation less than $80 \mathrm{~mm}$. These stations are ultimately classified as desert or grassland based on spring precipitation (rule $6,20 \mathrm{~mm} / \mathrm{mo}$ ) and tall or short grass based on summer precipitation (rule $7,70 \mathrm{~mm} / \mathrm{mo}$ ).

The remaining stations will be classified as either shrublands, open forest (savanna), or grasslands potentially supporting woody species. Shrubland and open forest are distinguished depending on whether winter rains are above or below $305 \mathrm{~mm}$ (rules $9,11,13$, 14). Each type (shrub or tree) can be broadleaf or microphyllous (small leaf), depending on the level of summer rains (rules 10,12), reflecting again the inferred vapor-pressure gradient across the leaf surface. If summer rains are sufficient to support a broadleaf type (rule 10), the result is either a broadleaf, tall-grass savanna or tall-grass shrub savanna. In either case, secondary rules are invoked to classify these sites as tall grass prairie, with the principal mechanism for grass dominance assumed to be fire.

Given sufficient winter rain to support shrubs or open forest (rule 5), but less than $70 \mathrm{~mm} / \mathrm{mo}$ of summer rain (rule 10 ), only a xeromorphic leaf structure can be supported. The tree form will be conifer and could be a xeric conifer savanna, such as ponderosa pine or a smaller stature but more dense pygmy forest of pinyon pine and juniper. In either case, the conifer leaf area is comparatively low. If only the shrub form can be supported (rule 14), the shrubs would be microphyllous. If summer rain is more than $28 \mathrm{~mm} / \mathrm{mo}$ and spring rain more than $20 \mathrm{~mm} / \mathrm{mo}$ (rule 8), then a well developed short grass community can be supported. Under these conditions, secondary rules are again invoked to remove the woody component (rule 13), and the communities are classified as short grass. Below $28 \mathrm{~mm} / \mathrm{mo}$ of summer rain, the grassland is of lower biomass, weakening the secondary rules and resulting in either a shrub or pygmy forest savanna, depending on winter rain (rule 14).

\section{Model Calibration}

The model parameters were adjusted to provide an optimal fit to the specified biome boundaries. This was accomplished iteratively by visual examination of the residuals and calculation of percent correct classification. Two classes of parameters require calibration:

- Thermal constraints controlling the beginning and end of seasons.

- Precipitation thresholds within seasons for different life-forms.

These must initially be calibrated in tandem, with sensitivity of both classes being examined. However, once the thermal thresholds are set, primary calibration is with the precipitation thresholds. Future versions of the model that incorporate PET will use the PET-minus-precipitation estimates in conjunction with thermal information to control seasonal timing and length.

Most rules exhibit one or more "balance" points. That is, increasing or decreasing the value of a parameter may continue to increase the correct classification of a particular biome, but there will be a point above or below which further adjustment occurs at the expense of correct classification in other biomes. The parameters were adjusted close to these balance points. Some parameters were clearly more sensitive than others, but we have not attempted a formal sensitivity analysis. 
The site-specific accuracy of the calibration was $79 \%$. Highest success was $94 \%$ in the eastern United States forests and lowest was $0 \%$ for the 11 grassland stations in the central valley of California (Figure 5, Table 1). The current model does not subdivide the eastern forest into the three subsections. When these rules are implemented, errors in classification undoubtedly will occur near the ecotones. A few sites near the border between the northern hardwoods and the boreal forest were classified as conifer, a reasonable occurrence. The mixed forests of the Rocky Mountains were only predicted at $19 \%$ accuracy (28\% northern Rockies, $12 \%$ southern Rockies (Table 1). The next lowest success was $70 \%$ for the tall grass prairie; the remaining biomes were predicted at better than $80 \%$ accuracy.

Closer examination of the residuals reveals that the model is more accurate than these indications, since pre-classification error is incorporated in the results. The California grasslands were predicted as conifer forest (45\%), shrubland (36\%), and pinyon-juniper $(P-J)$ woodland $(18 \%)$. Given the wet winters and very dry summers, these predictions may be quite reasonable. The conifer forest and P-J woodland stations cluster in the north end of the valley and at the boundaries with the neighboring conifer forests. These could be accurate classifications given the potential inaccuracies of the pre-classification biome map. A shrubland classification for the remaining sites may also be acceptable.

Remember that the rule-based classifications have been simplified to indicate only the dominant life-form, even if a mixture is actually being selected (Figure 4). The shrubland classification in the current configuration of rules is actually a mixture of shrub and short grass life-forms (rule 14). Climatically, the mixed shrub/grass classification for the central valley is quite reasonable; however, the relative mix of shrubs and grass is likely inaccurate in that the model does not yet account for the unusually long spring period over which grass biomass would build. Given sufficient grass biomass, the natural and anthropogenic influence of fire could have rendered the valley more of a monotypic grassland (Vankat 1979). Other possibilities for a lack of shrubs in the central valley include: (1) the presence of fine surface soils that might hinder percolation of deep soil water, and (2) the lack of sufficient summer rain usually necessary for establishment of shrubs (Neilson 1986).

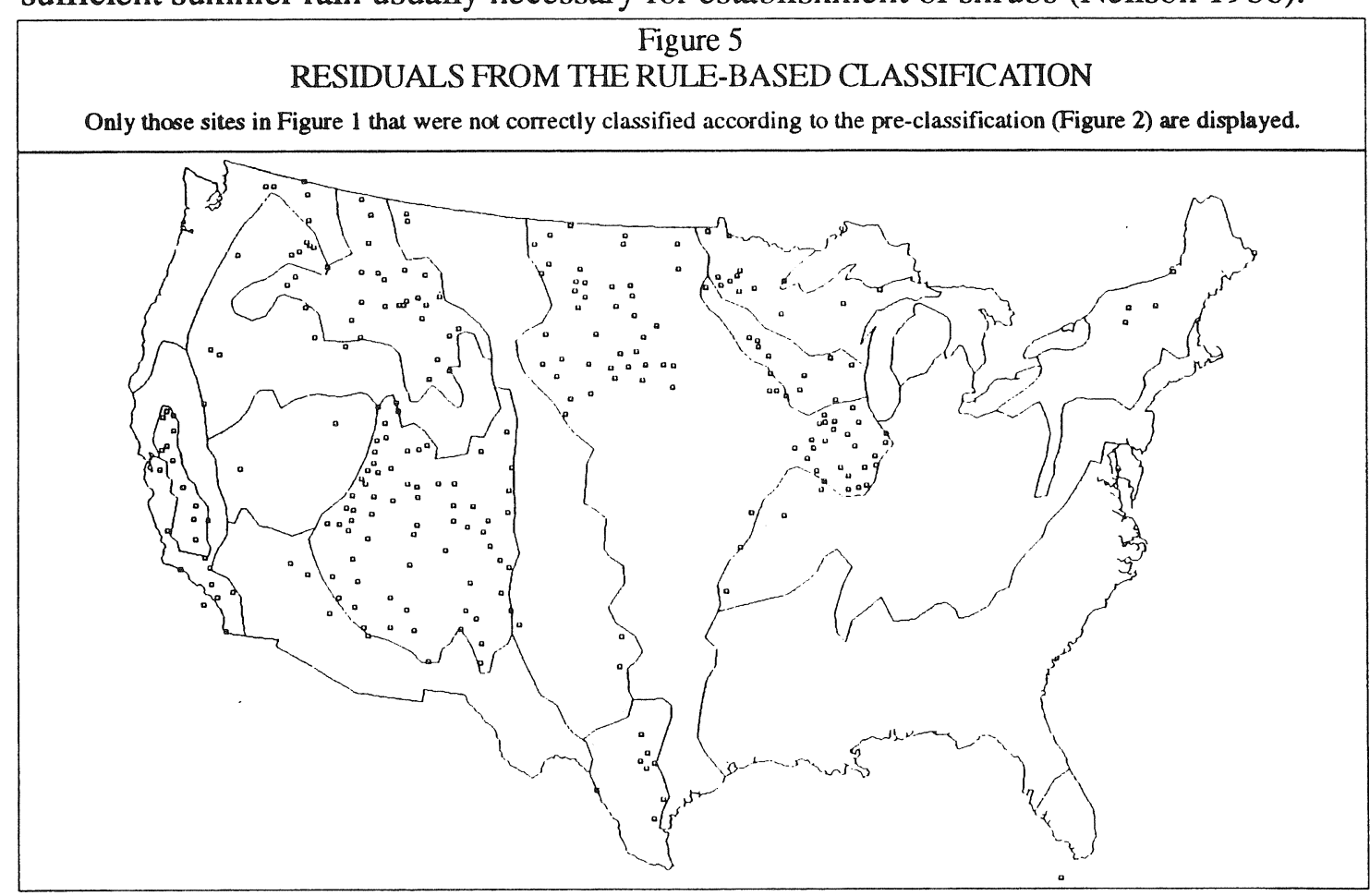


Table 1

SUMMARY OF CLASSIFICATIONS

Entries are percentages.

Bold numbers correspond to groupings of similar biomes. Italics highlight the correct classification category.

Numbers in parentheses are sample sizes and percentages if the northern mixed grass prairie of Küchler (1964?) is considered short grass prairie as determined by the rule-base. The current configuration of rules does not explicitly attempt to distinguish mixed grass as intermediate between short and tall grass.

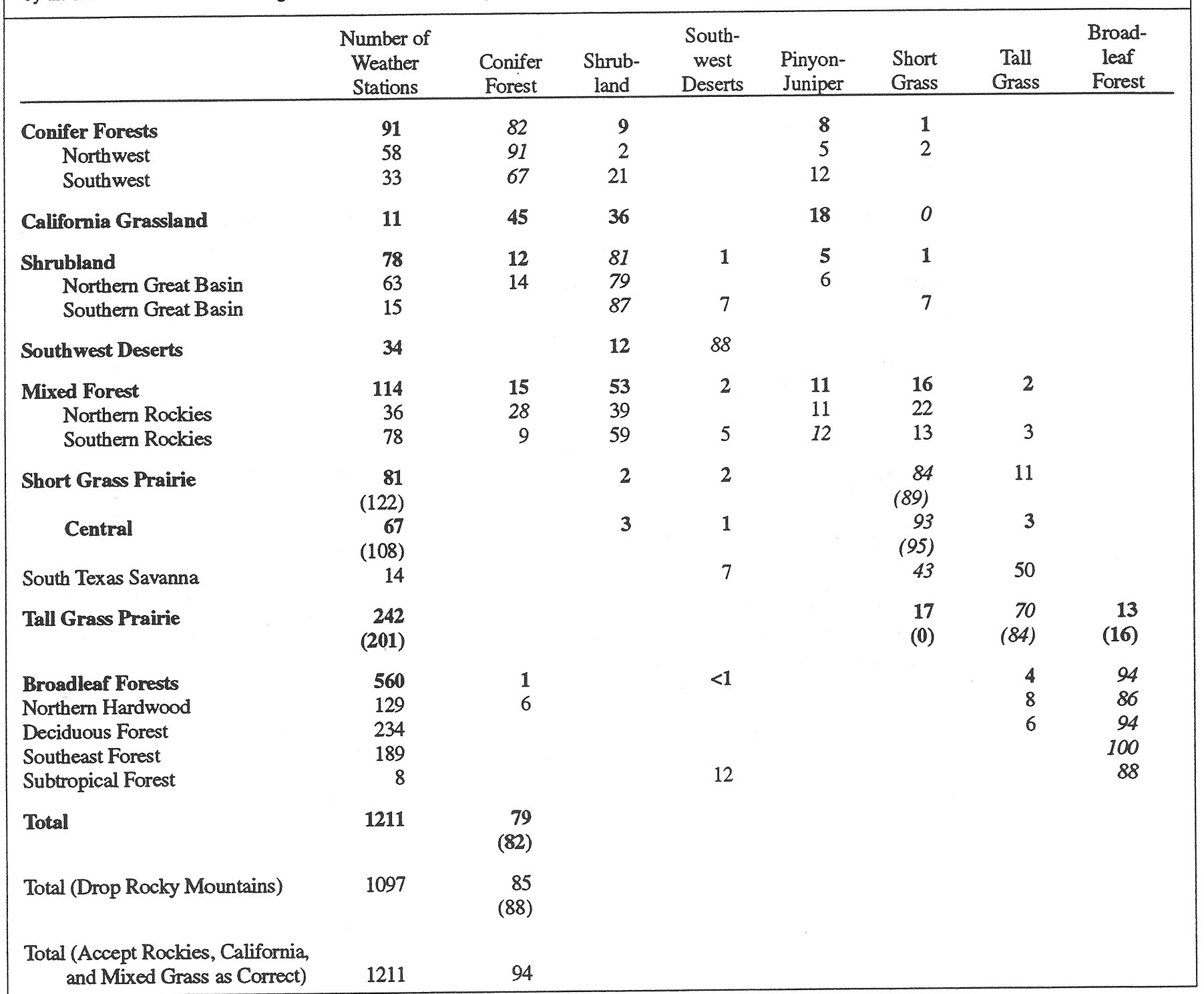

Both the northern and southern Rocky Mountain regions were poorly predicted. The over-simplistic pre-classification into one category each - conifers in the north and pinyon-juniper in the south - does not capture the vertical zonation of vegetation in these regions. Most of the weather stations in this highly dissected terrain occur in valley bottoms often dominated by shrubland or grassland (Küchler 1964, Vankat 1979). Classifications for the northern Rocky Mountains include conifer (28\%), pinyon-juniper (11\%), shrubland (39\%), and short grass (22\%). The southern Rocky Mountains are warmer, more xeric in winter, and wetter in summer, with conifer (9\%), pinyon-juniper (12\%), shrubland (59\%), desert (5\%), short grass (13\%), and tall grass (3\%). We examined most of these stations individually and concluded that these classifications are generally accurate. If the Rocky Mountain rule-based classifications are accepted as correct, model performance shifts from $79 \%$ to $90 \%$ overall. If the Rocky Mountains are removed from the classification, the performance is $85 \%$ (Table 1 ). 
A third set of residual mis-classifications stems from $17 \%$ of the tall grass prairie stations being classified as short grass prairie. These stations are in a region in the northern plains designated by Küchler (1964) as mixed grass, a life-form for which we have not written a rule. Thus, our pre-classification as either short or tall grass is arbitrary. If these stations are accepted as correctly classified, performance of the model in the tall grass shifts from $70 \%$ to $84 \%$, and the overall rating increases from $79 \%$ to $82 \%$. If the mixed grass is accepted but both the Rockies and the central valley are excluded, accuracy of the model is $88 \%$. If both the Rocky Mountains and the mixed grass classifications are accepted, the overall accuracy shifts to $93 \%$. If the central valley classifications are also accepted, the overall accuracy is $94 \%$.

The remaining cluster of residuals occurs where much of the prairie peninsula is classified as broadleaf forest rather than grassland. Classification of the prairie peninsula has been a particular challenge to biogeographers and climatologists (Borchert 1950, Corcoran 1982, Küchler 1972, Manogaran 1983, Transeau 1935). There is considerable debate as to whether the prairie peninsula is climatically determined or whether man historically induced the prairie through fire (Vankat 1979). Fires clearly play a major role in reducing the dominance of woody vegetation. However, a climatic classification of the prairie peninsula, based on a moisture index of Thornthwaite, indicates that the region is climatically unique (Manogaran 1983). The current configuration of the rule-base lacks the PET calculations necessary to reflect this unique climatology. The next version will incorporate the PET calculations.

The prairie peninsula also occurs at the convergence of two air mass gradients (Bryson 1966). As a consequence, regional rainfall gradients are relatively shallow (Neilson et al. 1989) and should exhibit considerable year-to-year variability. We tested the sensitivity of the prairie-forest border to small changes in the winter rainfall threshold. The prairie peninsula was most sensitive to these changes; the border locations to the north and south were more stable. It is possible that year-to-year variability of weather patterns produces extreme years that preclude long-term maintenance of forest in the prairie peninsula. We expect the model rendition of the prairie peninsula will improve with future enhancements.

\section{Future Model Development}

The primary limitation of the current configuration of the model is that it simulates only the supply side of the water balance. The next enhancement will be to include the demand side as driven by PET. Precipitation thresholds will be reevaluated as a function of seasonal PET and seasonal rainfall supply. Within the water balance thresholds for each life-form, water balance will be treated as a continuum and calculated using energy balance equations, allowing a prediction of leaf area as well as life-form (Woodward 1987). Regional information on soil water holding capacity and texture will be required to fine-tune the regional water balance estimates. The continued use of thresholds in the model recognizes the use of thresholds in defining physiognomic distinctions. It may be possible in the future to loosen this constraint and treat life-form physiognomies as a continuum. Grass physiognomy extends toward large and woody, as in bamboo, and woody plants extend toward small ephemerals, as in many semi-arid species.

With the incorporation of PET, the model will be complete enough for a preliminary estimate of $2 \times \mathrm{CO}_{2}$ impacts on biome distribution over the conterminous United States. 
Qualitative estimates have been made based on the conceptual precursor to this model (Neilson et al. 1989). Biome boundaries are expected to shift several degrees of latitude and hundreds of meters of elevation.

Temperature constraints will also be added to the model to differentiate the mixed forests of the southeastern United States from the eastern deciduous forest and the temperate forest from the boreal forest (Figure 2). The model will also be extended to both boreal and tropical regions. These extensions will require very different kinds of rules than those developed for temperate zone biomes. For example, the current, thermally defined summer shortens with increasing latitude and disappears at about the latitude of the boreal forest. Likewise, the thermally defined winter does not occur in the subtropics, i.e., the vicinity of Florida. Transect analyses, as applied in the United States (Neilson et al. 1989), will be extended to other parts of the world to assist in formulation of additional rules.

Calibration of the model with regard to secondary rules, those invoking fire and biotic interactions, will require continuing investigation. Since the natural environment expresses the influence of these processes, it is particularly difficult to assign thresholds that adequately constrain biomes in the absence of secondary rules. For example, the winter precipitation threshold below which shrubs cannot be supported is currently set at $80 \mathrm{~mm}$ (rule 5, Figure 4). This produces shrubland in the Great Basin and desert in the Southwest. It also produces shrubland throughout the Great Plains. The simultaneous presence of grassland in the plains invokes the secondary rules to shift the biome classification to grassland. If the winter threshold (rule 5) is set to $200 \mathrm{~mm}$, fewer plains sites are attributed a shrub component, but the Great Basin becomes a desert. The Great Basin is characterized by a series of parallel mountain ranges separated by narrow valleys wherein the shrublands occur. The mountains collect winter precipitation, which can run off and infiltrate to deep soil layers in adjacent alluvial fans (Schlesinger and Jones 1984), providing greater deep soil water for support of shrubland than incident precipitation alone. Thus, we are left with a choice for secondary rules:

- Invoke fire in the plains to remove shrubs, or

- Invoke "run on" in the Great Basin to augment deep soil water and support shrubs.

The first option is used now, but there is little information as to the comparative degree to which these processes control shrubland distribution.

The model could be described as a demographic rather than an ecosystem model, since it simulates life-form (Beard 1978) but does not address nutrient dynamics (O'Neill et al. 1986). Alternative approaches to simulation of productivity and nutrient dynamics will be explored (e.g., Jarvis and Leverenz 1983). Once the model incorporates an energy balance approach to determining the life-form thresholds, water flux through the ecosystems will be directly calculated. This information, coupled with water-use efficiency and energy-use efficiency parameters (Landsberg and McMurtrie 1985, Linder 1985, Montieth 1977, Tucker et al. 1986) should allow estimates of potential primary productivity. Potential productivity could be modulated by nutrient-use efficiency and soil nitrogen estimates (Prescott et al. 1989, Vitousek 1984). Decomposition rates could be parameterized as functions of temperature and moisture (Meentemeyer 1978). 
Increased levels of $\mathrm{CO}_{2}$ are known to increase productivity and water-use efficiency in many plants (Strain and Cure 1985). The potential importance of these effects at landscape and biome scales is under debate. If these effects are significant at a regional scale, then the impacts of climatic change could be considerably ameliorated, assuming the gradually increasing influence of direct effects of $\mathrm{CO}_{2}$ is not preceded by adverse climatic effects of increasing trace gases, such as widespread drought. Also, even if direct effects prove important over a wide array of plants, it is not clear how much influence plant-scale water balance, modulated by the stomata, has over landscape-scale water balance. The latter appears to be largely driven by radiation and modulated by root density and depth and by leaf area (Federer 1982, Jarvis and McNaughton 1986). Clearly, stomatal processes will control rates of drying; however, the accurate simulation of drying curves may not be important at time steps of one month (Cowan 1965).

A particularly important enhancement to the model will be to move from steady state to transient dynamics. The potential spatial redistribution of biomes could be mediated by major diebacks or declines in some areas and advances in others (Neilson et al. 1989, Solomon 1986, Overpeck et al. 1990). Simulation of these dynamics will require both demographic and ecosystem processes. Dispersal of important tree types is expected to lag considerably behind the rapidity of climatic change and potential movement of boundaries (Davis 1986, Smith and Tirpak 1989). It will be important to incorporate functional categories of seed dispersal in the life-history characterizations (Beard 1978). As extratropical forests shift toward the poles, large areas of their current distributions could undergo severe, drought-induced decline and dieback (Neilson et al. 1989, Overpeck $e t$ al. 1990). These would be susceptible to fire. The release of $\mathrm{CO}_{2}$ into the atmosphere from these fires and subsequent decay of the remaining dead biomass could produce a positive feedback to the "greenhouse effect" (Neilson et al. in prep.). The regrowth of burned landscapes and the potential expansion of the tropics could ameliorate this $\mathrm{CO}_{2}$ pulse to some extent. We have begun modeling these processes and will incorporate these dynamics into future versions of the model.

Simulation of transient dynamics could also be necessary for accurate delineation of some biome boundaries. Sensitivity analyses on the winter precipitation parameter separating closed from open forest $(375 \mathrm{~mm})$, indicates the eastern extent of the prairie peninsula is quite sensitive to this parameter. Year-to-year variability of rainfall could be shifting this climatic transition considerably (Coupland 1958, Küchler 1972). Even though the average climate of the prairie peninsula may be suitable for forest establishment and growth, the extremes due to natural climatic variability could preclude their long-term viability in the region.

As model development continues, calibration and validation will be increasingly important. Although the focus has been on enhancements to the model, it is apparent that the calibration is very dependent on accuracy of the pre-classification. In the Rocky Mountains, for example, correct model calibration will require a much higher spatial resolution of biome type than needed for less mountainous terrain. Literature and existing maps will be useful in this endeavor. However, satellite technology has the potential to provide this classification at a comparatively high resolution (Tucker et al. 1985). Remote classification of vegetation should be a high priority for all the world's vegetation.

Three approaches to model validation will be explored: 
- Implementation on another continent.

- Simulation of paleoclimates (Webb et al. 1990).

- Rescaling the model to a smaller, but heterogeneous extent.

We will attempt to validate the model through extension to other continents, attempts to reconstruct past vegetation, and attempts to rescale the model. Since the model is physically driven and is purported to be mechanistically based, it should apply at any scale of resolution. Thus, application to a heterogeneous watershed such as the Colorado drainage would be an interesting test of the model.

\section{Conclusions}

The initial stage of development of a rule-based, mechanistic model of vegetative life-form distribution has been described. Different life-form mixtures deduced from the rules produce different biomes, with demonstrated prediction potential of up to $94 \%$ accuracy. The current configuration of rules is based entirely on the seasonal patterns of regional water balance and the relation of these patterns to different plant life-forms. The apparent success of the model makes two important points.

- Regional water balance does appear to be a critical climatic mechanism determining plant distributions.

- Success of the model, even when the demand side of regional water balance (PET) was not directly considered, implies that on regional scales water balance is currently in equilibrium with the vegetation.

It follows that the atmospheric demand for water (PET) is in balance with the supply of water through transpiration. The regional rate of transpiration, according to theory (Woodward 1987), should be related to the amount of leaf area (biomass) over that region. The amount of leaf area over a region should be a direct result of ecosystem feedback processes that select for a specific leaf area as a function of water supply and atmospheric demand. The implication is that ecosystems are precariously balanced with respect to regional water balance and that a rapid change in either supply or demand for water could produce a catastrophic response from regional vegetation.

Being mechanistic in concept, future model enhancements to incorporate ecosystem and spatial demographic processes with temporal dynamics should be relatively straightforward, albeit challenging to implement. The value of these efforts, particularly when coupled with global atmosphere models and land-use characteristics, should be realized in a much improved predictive potential of global change and biosphere/atmosphere feedbacks.

\section{References}

Abrams, M.D., A.K. Knapp, and L.C. Hulbert. 1986. "A Ten-Year Record of Aboveground Biomass in a Kansas Tallgrass Prairie: Effect of Fire and Topographic Position". Amer. J. Bot., 73(10):15091510 . 
Beard, J.S. 1978. "The Physiognomic Approach" in Classification of Plant Communities. Ed. Robert H. Whittaker. The Hague, Netherlands.

Borchert, J.R. 1950. "The Climate of the Central North American Grassland". Annals of the Association of American Geographers, 15(1):1-38.

Box, E.O. 1981. Macroclimate and Plant Forms: An Introduction to Predictive Modeling in Phytogeography. Dr. W. Junk Publishers. The Hague.

Bryson, R.A. 1966. "Air Masses, Streamlines, and the Boreal Forest". Geographical Bulletin $8(3): 228-269$.

Burke, M. J., L.V. Gusta, H.A. Quamme, C.J. Weiser, and P.H. Li. 1976. "Freezing Injury in Plants". Annual Review of Plant Physiology, 27:507-528.

Corcoran, W.T. 1982. "Moisture Stress, Mid-Tropospheric Pressure Patterns, and the Forest/Grassland Transition in the South Central States". Physical Geography 3(2):148-159.

Coupland, R.T. 1958. "The Effects of Fluctuations in Weather upon the Grasslands of the Great Plains". The Botanical Review, 23(5):273-317.

Cowan, I.R. 1965. "Transport of Water in the Soil-Plant-Atmosphere System". J. Applied Ecology, 2:221239.

Davis, M.B. 1986. "Lags in the Response of Forest Vegetation to Climatic Change" in Climate-Vegetation Interactions. Ed. C. Rosenzweig and R. Dickson. OIES-UCAR, Boulder, CO.

Dice, L.R. 1943. The Biotic Provinces of North America. University of Michigan Press. Ann Arbor. pp. 1-79.

Federer, C.A. 1982. "Transpirational Supply and Demand: Plant, Soil, and Atmospheric Effects Evaluated by Simulation". Water Resources Research, 18(2):355-362.

Jarvis, P.G., and J.W. Leverenz. 1983. "Introduction: Temperate Forest" in Productivity of Temperate, Deciduous, and Evergreen Forests. Encyclopedia of Plant Physiology. Springer-Verlag. Berlin. pp. 243-280.

Jarvis, P.G., and K.G. McNaughton. 1986. "Stomatal Control of Transpiration: Scaling Up from Leaf to Region". Advances in Ecological Research, 15:1-49.

Küchler, A.W. 1972. "The Oscillations of the Mixed Prairie in Kansas". Erdkunde, Archiv fuir wissenschaftliche Geographie, 26:120-129.

1964. The Potential Natural Vegetation of the Conterminous United States. American Geographical Society Special Publication No. 36.

Landsberg, J.J., and R. McMurtrie. 1985. "Models Based on Physiology as Tools for Research and Forest Management" in Research for Forest Management. Ed. J.J. Landsberg and W. Parsons. Proceedings of a Conference Organized by the Division of Forest Research, CSIRO, May 21-25, 1984. Canberra, Australia.

Linder, S. 1985. "Potential and Actual Production in Australian Forest Stands" in Research for Forest Management. Ed. J.J. Landsberg and W. Parsons. CSIRO, Australia. 
Major, J. 1963. “A Climatic Index to Vascular Plant Activity”. Ecology, 44:485-498.

Manogaran, C. 1983. "The Prairie Peninsula: A Climatic Perspective". Physical Geography, 4(2):153-166.

Marshall, J.D., and R.H. Waring. 1984. "Conifers and Broadleaf Species: Stomatal Sensitivity Differs in Western Oregon". Can. J. For. Res., 14:905-908.

Meentemeyer, V. 1978. "Macroclimate and Lignin Control of Litter Decomposition Rates". Ecology, 59(3):465-472.

Monteith, J.L. 1977. "Climate and the Efficiency of Crop Production in Britain". Phil. Trans. R. Soc. Lond. B., 281:277-294.

Neilson, R.P. 1987. "Biotic Regionalization and Climatic Controls in Western North America". Vegetatio, 70:135-147.

1986. "High-Resolution Climatic Analysis and Southwest Biogeography". Science, 232:27-34.

Neilson, R.P., G.A. King, R.L. DeVelice, J. Lenihan, D. Marks, J. Dolph, B. Campbell, and G. Glick. 1989. Sensitivity of Ecological Landscapes and Regions to Global Climate Change. U.S. Environmental Protection Agency, Environmental Research Laboratory. Corvallis, OR.

Neilson, R.P., and L.H. Wullstein. 1983. "Biogeography of Two Southwest American Oaks in Relation to Atmospheric Dynamics". J. of Biogeography, 10:275-297.

O'Neill, R.V., D.L. DeAngelis, J.B. Waide, and T.F.H. Allen. 1986. "A Hierarchical Concept of Ecosystems" in Monographs in Population Biology. Ed. R.M. May. Princeton University Press. Princeton, NJ.

Overpeck, J.T., D. Rind, and R. Goldberg. 1990. "Climate-Induced Changes in Forest Disturbance and Vegetation". Nature, 343:51-51.

Prentice, K.C. 1990. "Bioclimatic Distribution of Vegetation for GCM Studies". J. Geo. Res. 95:1181111830.

Prescott, C.E., J.P. Corbin, and D. Parkinson. 1989. "Biomass, Productivity, and Nutrient-Use Efficiency of Aboveground Vegetation in Four Rocky Mountain Coniferous Forests". Can. J. Res., 19:309-317.

Quinlan, F.T. , T.R. Karl, and C.N. Williams, Jr. 1987. United States Historical Climatology Network (HCN) Serial Temperature and Precipitation Data. Carbon Dioxide Information Analysis Center, NDP019. Oak Ridge National Laboratory. Oak Ridge, TN.

Runkle, J.R. 1985 "Disturbance Regimes in Temperate Forests" in The Ecology of Natural Disturbance and Patch Dynamics. Ed. S.T.A. Pickett and P.S. White.

Running, S.W. 1975. "Environmental Control of Leaf Water and Conductance in Conifers". Can. J. Res. For. Res., 6:104-112.

Schlesinger, W.H., and C.S. Jones. 1984. "The Comparative Importance of Overland Runoff and Mean Annual Rainfall to Shrub Communities of the Mojave Desert". Bot. Gaz., 145(1):116-124. 
Smith, J.B., and D. Tirpak (eds.). 1989. The Potential Effects of Global Climate Change on the United States. Report to Congress. U.S. Environmental Protection Agency. EPA-230-05-89-050. Washington, DC.

Solomon, D.M. 1986. “Transient Response of Forests to $\mathrm{CO}_{2}$-Induced Climate Change: Simulation Modeling Experiments in Eastern North America". Oecologia, 68:567-579.

Stephenson, N.L. 1990. "Climatic Control of Vegetation Distribution: The Role of the Water Balance". American Naturalist, 135:649-670.

Strain, B.R. and J.D. Cure. 1985. Direct Effects of Increasing Carbon Dioxide on Vegetation. U.S. Dept. of Energy, Carbon Dioxide Research Division DOE/ER-0238. Washington, DC.

Thornthwaite, C.W. 1948. "An Approach Toward a Rational Classification of Climate". Geographical Review, 38:55-94.

Thornthwaite, C.W., and J.R. Mather. 1955. The Water Balance. Publications in Climatology, Vol. VIII, No. 1. Drexel Institute of Technology. Centerton, NJ.

Transeau, E.N. 1935. “The Prairie Peninsula”. Ecology, 16(3):423-439.

Tucker, C.J., I.Y. Fung, C.D. Keeling, and R.H. Gammon. 1986. "Relationship Between Atmospheric $\mathrm{CO}_{2}$ Variations and a Satellite-Derived Vegetation Index". Nature, 319:195-199.

Tucker, C.J., J.R.G. Townshend, and T.E. Goff. 1985. "African Land-Cover Classification Using Satellite Data". Science, 227:369-375.

US WEST. 1988a. Climatedata User's Manual: TD3200 Summary of the Day - Cooperative Observer Network. US WEST Optical Publishing. Denver, CO.

US WEST. 1988b. Hydrodata User's Manual: USGS Daily and Peak Values, Version 2.0. US WEST Optical Publishing. Denver, CO.

Vankat, J.L. 1979. The Natural Vegetation of North America. John Wiley and Sons. New York.

Vitousek, P.M. 1984. "Litterfall, Nutrient Cycling, and Nutrient Limitation in Tropical Forests". Ecology, 65(1):285-298.

Waring, R.H., and J.F. Franklin. 1979. "Evergreen Coniferous Forests of the Pacific Northwest". Science 204:1380-1386.

Webb, T.III, P.J. Bartlein, and J.E. Kutzbach. 1990. "Climatic Change in Eastern North America During the Past 18,000 Years: Comparisons of Pollen Data with Model Results" in North America and Adjacent Oceans During the Last Deglaciation. Ed. W.F. Ruddiman, and H.E. Wright. Geology of North America. Geological Society of America. Boulder, CO.

Woodward, F.I. 1987. Climate and Plant Distribution. Cambridge University Press. London, England. 